\title{
Robust Humoral and Cellular Immune Responses to Pertussis in Adults After a First Acellular Booster Vaccination
}

\begin{abstract}
Saskia van der Lee ${ }^{1,2 *}$, Debbie M. van Rooijen ${ }^{1}$, Mary-Lène de Zeeuw-Brouwer', Marjan J. M. Bogaard', Pieter G. M. van Gageldonk', Axel Bonacic Marinovic', Elisabeth A. M. Sanders ${ }^{1,2}$, Guy A. M. Berbers ${ }^{1}$ and Anne-Marie Buisman ${ }^{1 *}$

${ }^{1}$ Centre for Infectious Disease Control, National Institute for Public Health and the Environment (RIVM), Bilthoven, Netherlands, ${ }^{2}$ Department of Paediatric Immunology and Infectious Diseases, Wilhelmina Children's Hospital, University Medical Centre, Utrecht, Netherlands
\end{abstract}

OPEN ACCESS

Edited by: Ali Ellebedy, Washington University in St. Louis, United States

Reviewed by: Rustom Antia, Emory University, United States

Jennifer Nayak,

University of Rochester, United States

${ }^{*}$ Correspondence:

Saskia van der Lee saskia.van.der.lee@rivm.nl;

Anne-Marie Buisman annemarie.buisman@rivm.nı

Specialty section: This article was submitted to Immunological Memory, a section of the journal

Frontiers in Immunology

Received: 09 January 2018 Accepted: 20 March 2018 Published: 04 April 2018

Citation: van der Lee S, van Rooijen DM, de Zeeuw-Brouwer M-L, Bogaard MJM, van Gageldonk PGM,

Marinovic $A B$, Sanders EAM, Berbers GAM and Buisman $A M$ (2018) Robust Humoral and Cellular

Immune Responses to Pertussis in Adults After a First Acellular Booster Vaccination.

Front. Immunol. 9:681. doi: 10.3389/fimmu.2018.00681
Introduction: To reduce the pertussis disease burden, nowadays several countries recommend acellular pertussis (aP) booster vaccinations for adults. We aimed to evaluate the immunogenicity of a first adult aP booster vaccination at childbearing age.

Methods: In 2014, healthy adults aged $25-29$ years $(n=105)$, vaccinated during infancy with four doses of whole-cell pertussis (wP) vaccine, received a Tdap (tetanus, diphtheria, and $\mathrm{aP}$ ) booster vaccination. Blood samples were collected longitudinally pre-booster, 2 and 4 weeks, and 1 year and 2 years post-booster. Tdap vaccine antigen-specific antibody levels and memory B- and T-cell responses were determined at all time points. Antibody persistence was calculated using a bi-exponential decay model.

Results: Upon booster vaccination, the lgG levels specific to all Tdap vaccine antigens were significantly increased. After an initial rapid decline in the first year, PT-IgG antibody decay was limited (15\%) in the second year post-booster. The duration of a median level of PT-IgG $\geq 20 \mathrm{IU} / \mathrm{mL}$ was estimated to be approximately 9 years. Vaccine antigenspecific memory B- and T-cell numbers increased and remained thigh levels although a significant decline was observed after 4 weeks post-booster. However, Th1, Th2, and Th17 cytokine production remained above pre-booster levels for 2 years.

Conclusion: The Tdap booster vaccination in wP-primed Dutch adults induced robust long-term humoral and cellular immune responses to pertussis antigens. Furthermore, PT-IgG levels are predicted to remain above the presumed protective cut-off for at least 9 years which might deserves further attention in evaluating the current recommendation to revaccinate women during every new pregnancy.

Keywords: pertussis, adult immunization, antibody decay, memory B-cells, memory T-cells

\section{INTRODUCTION}

The incidence of clinical pertussis cases strongly declined after the introduction of whole-cell pertussis (wP) vaccines in infant national immunization programs (NIP) in the 1940 and 1950s (1). Despite a consistently high vaccination coverage, an increase in numbers of pertussis cases is observed in many countries and in all age groups (2-5). Consequently, in addition to pre-school acellular 
pertussis $(\mathrm{aP})$ booster vaccinations, several countries have implemented aP booster vaccinations for adolescents and adults (6-8). Furthermore, to protect unvaccinated infants against pertussis, pregnant woman are advised to receive maternal aP booster vaccination in more than 25 countries $(9-11)$.

Waning immunity after vaccination and natural infection as well as the switch from wP to aP vaccines in the primary infant vaccination series are thought to have contributed to the pertussis resurgence (12-14). The switch from wP to aP vaccines for infants occurred in January 2005 in the Netherlands, which is rather late compared with other high-income countries. After an aP vaccination in adults, low pertussis antibody levels, and in particular low anti-pertussis toxin (PT) antibodies, that are considered the most protective against clinical B. pertussis symptoms, have been observed already within 1 year $(15,16)$. These studies were, however, conducted in a period with a presumed lower circulation of $B$. pertussis (late 1990s) in comparison to the past decades $(17,18)$.

Nowadays, increased circulation of $B$. pertussis might allow for more natural boosting of the immune system, and affect antibody kinetics as well as cellular immunity after an adult aP booster vaccination. We aimed to evaluate the long-term immunogenicity of a first adult aP booster vaccination at childbearing age. A bi-exponential antibody decay model was used to predict the duration of antibody persistence to PT after vaccination. This study provides valuable information for the improvement of adult and maternal pertussis vaccination programs.

\section{MATERIALS AND METHODS}

\section{Study Design and Participants}

In this phase IV, longitudinal intervention study, healthy Dutch adults 25-29 years of age were recruited to receive a tetanus, diphtheria, and acellular pertussis (Tdap) booster vaccination. Exclusion criteria were pregnancy at the start of the study; present severe disease or medical treatment that might interfere with study results; an adverse event after previous vaccinations; other pertussis vaccinations than those given according to the Dutch NIP; diphtheria and/or tetanus vaccination in the past 5 years; plasma products received in the past 6 months; any vaccination in the last month and/or antibiotic use or fever $\left(\geq 38^{\circ} \mathrm{C}\right)$ in the 2 weeks before study enrollment. Written informed consent was obtained at the start of the study. The study was approved by the Medical Ethics Review Committee North Holland (METC-NH, Alkmaar, the Netherlands) and registered at the European clinical trials database (2013-005355-32) and the Dutch trial register (www.trialregister.nl; NTR4494).

\section{Vaccination Background}

All participants had received the Dutch diphtheria, tetanus, whole-cell pertussis, and inactivated poliovirus combination vaccine (National institute for Public Health, Bilthoven, the Netherlands) according to the then NIP at 3, 4, 5, and 11 months of age. In this study, the participants received a Tdap booster vaccine (Boostrix ${ }^{\mathrm{TM}}$, GlaxoSmithKline, Rixensart, Belgium). The vaccine contained $8 \mu \mathrm{g}$ PT and filamentous hemagglutinin
(FHA), $2.5 \mu$ g pertactin (Prn), $\geq 2$ IU diphtheria toxoid (Dd), and $\geq 20$ IU tetanus toxoid (Td).

\section{Blood Samples}

Serum samples were collected just before, 14 days ( \pm 2 days), 28 days ( \pm 2 days), 1 year ( \pm 2 weeks), and 2 years ( \pm 2 weeks) after the Tdap booster vaccination. Sera were stored at $-20^{\circ} \mathrm{C}$ until analysis. From a randomly selected subset of 60 participants, additional blood was sampled in vacutainer cell preparation tubes containing sodium citrate (Becton Dickinson (BD) Biosciences, San Jose, CA, USA). PBMCs were isolated within $16 \mathrm{~h}$, and stored at $-135^{\circ} \mathrm{C}$ as described previously (19).

\section{Serological Analysis}

PT-, FHA-, and Prn-specific IgG and IgA, and Dd- and tetanus toxin (TT)-specific IgG antibody concentrations were quantified using the fluorescent-bead-based multiplex immunoassay (MIA) as described (20-22). To express pertussis-IgG and IgA concentrations in international units (IU) per $\mathrm{mL}$, the WHO international standard (pertussis antiserum first international standard, 06/140, NIBSC) was used. A PT-IgG concentration of $20 \mathrm{IU} / \mathrm{mL}$ was used as an arbitrary cut-off for protection (23) and $50 \mathrm{IU} / \mathrm{mL}$ to indicate an infection with pertussis in the preceding years $(17,20)$. An IgA concentration $\geq 1 \mathrm{IU} / \mathrm{mL}$ was used as seropositive.

From 42 longitudinal samples, the PT- and Prn-IgG avidity was determined using the MIA with minor modifications (24), using $1.5 \mathrm{M}$ (for PT) and 2.5 M (for Prn) ammonium thiocyanate $\left(\mathrm{NH}_{4} \mathrm{SCN}\right)$. The geometric mean avidity index (GMAI) was expressed as the percentage of antibodies that remained bound to PT- or Prn-conjugated beads after $\mathrm{NH}_{4} \mathrm{SCN}$ treatment in comparison to untreated (PBS) samples.

\section{Flow Cytometry}

The absolute numbers of circulating B-cells and B-cell subsets were determined in 60 paired samples before and 2 weeks after the booster vaccination with a lyse-no-wash protocol using TruCOUNT tubes (BD Biosciences). The fluochrome-conjugated antibodies CD19(J3-119)-PE-Cy7 (Beckman Coulter, Fullerton, CA, USA), CD27(M-T271)-BV421, IgD(IA6-2)-FITC (both from Biolegend, San Diego, CA, USA), and CD38(HB7)APC-H7 (BD Biosciences) were used. Samples were measured using a LSRFortessa flow cytometer (BD Biosciences). The B-cell population in PBMCs before and after culture was determined using CD19-PerCPCy5.5 (BD Biosciences), and samples were measured on a FacsCanto flow cytometer (BD Biosciences). Data were analyzed using FACSDiva ${ }^{\mathrm{TM}}$ v8 (BD Biosciences) and FlowJo v10 (FlowJo company, Ashland, OR, USA) with a gating strategy as described (25).

\section{Antigen-Specific B- and T-cell Responses}

From 30 participants, vaccine antigen-specific B- and T-cell responses were determined. For B-cell responses, PBMCs were polyclonally stimulated for 5 days after which the number of specific IgG memory B-cells $/ 10^{5} \mathrm{CD} 19^{+}$cells was determined in PT-, FHA-, Prn-, and Td-specific ELISpot assays (19). Per 
participant, samples of different time points were determined simultaneously. Lower limit of quantification was 0.5 spots $/ 10^{5}$ CD $19^{+}$cells.

For T-cell responses, PBMCs were stimulated for 5 days with PT (heat inactivated), FHA, Prn, Dd, or Td after which supernatants were collected and stored at $-80^{\circ} \mathrm{C}(26)$. Unstimulated and pokeweed mitogen-stimulated cells served as negative and positive controls, respectively. The cytokines interferon-gamma (IFN- $\gamma$ ) (Th1), interleukin-13 (IL-13) (Th2), IL-17 (Th17), and IL-10 (Treg) were quantified in the supernatants using an in-house MIA developed according to de Jager et al. (27) and calibrated against the Bio-Plex cytokine assay kit (Bio-Rad Laboratories, Hercules, CA, USA).

\section{Statistical Analysis}

Geometric mean concentrations with corresponding 95\% confidence intervals were calculated for vaccine antigen-specific IgG, IgA, and cytokine concentrations. Numbers of vaccine antigen-specific memory B-cells are reported as geometric mean values $/ 10^{5} \mathrm{CD} 19^{+}$cells. The mean percent reduction of the IgG concentrations was calculated between the different time points after vaccination. The kinetics of IgG antibody levels was determined with a bi-exponential decay model as described (28).

Normal distribution of (log-transformed) data was confirmed prior to each analysis. Differences between time points were tested with paired sample $t$-tests (normal distributed data) or with Wilcoxon Signed Ranks tests (not normally distributed data). Correlations between variables were determined with Spearman correlations and linear regression analysis. A $p$-value $<0.05$ was considered statistically significant (two-sided test). Data were analyzed using GraphPad Prism v7 (GraphPad Software) and SPSS statistics v24 (IBM).

\section{RESULTS}

\section{Study Baseline Characteristics}

At the start of the study in April 2014, 105 participants received a Tdap booster vaccination (Figure 1). 2 years after the booster, $90.6 \%(96 / 106)$ of the participants completed all study visits and $\geq 100$ blood samples had been collected at every time point. Mean age at the start of the study was $27.6 \pm 1.4$ years and $34 \%$ was male (36/106).

\section{IgG and IgA Antibody Kinetics After the Tdap Booster Vaccination}

Before the Tdap booster vaccination, IgG levels against PT, FHA, and Prn were low (Figure 2 and Table 1), although 7\% (7/105) of the participants had a PT-IgG level $\geq 50 \mathrm{IU} / \mathrm{mL}$. 1 and 2 years postbooster, this percentage increased to respectively $78 \%(79 / 101)$ and $71 \%(71 / 100)$ of the participants. Following the Tdap booster

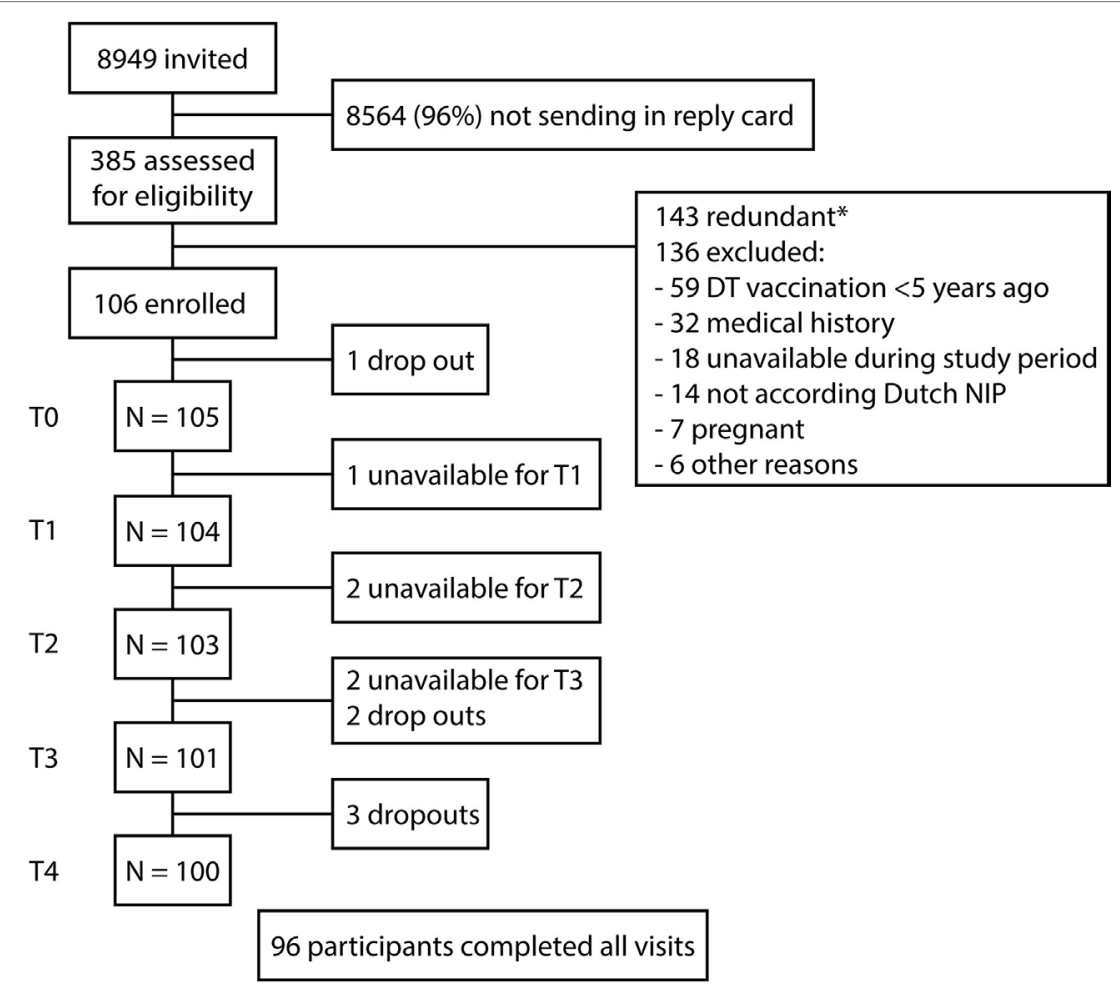

FIGURE 1 | Flow-chart of study enrollment. Schematic overview of the recruitment, enrollment, and the follow-up of the study participants. At the start of the study, Dutch participants 25-29 years of age received a tetanus, diphtheria, and acellular pertussis booster vaccination. Blood samples were collected before (T0), 2 weeks (T1), 4 weeks (T2), 1 year (T3), and 2 years (T4) after the booster vaccination. ${ }^{*} 143$ potential participants were excluded because the target for inclusion was achieved. 

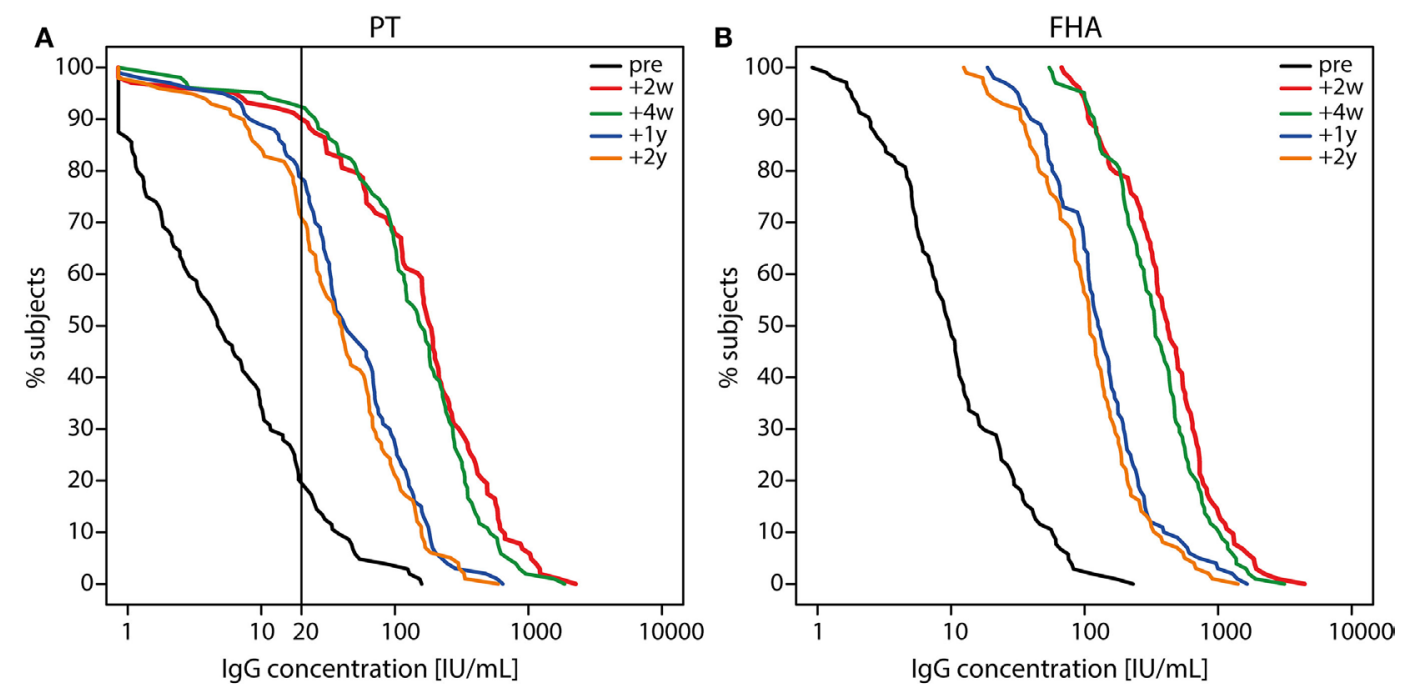

C

Prn

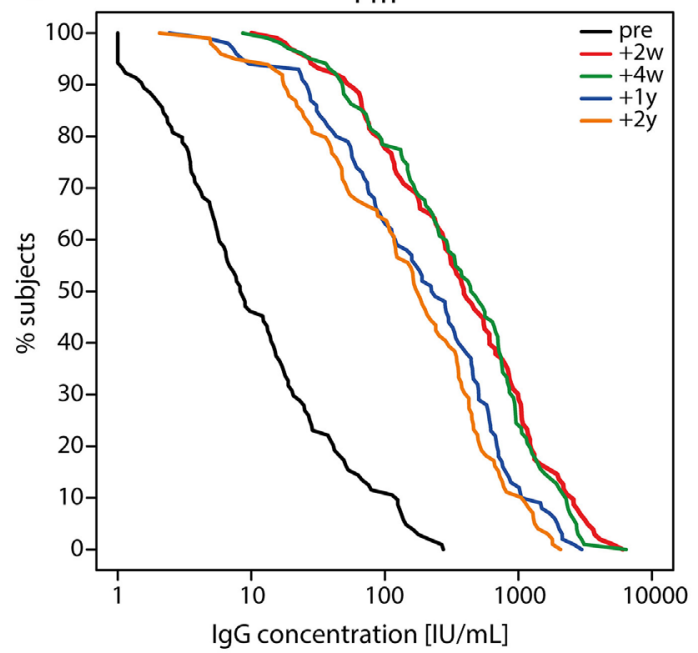

D Diphtheria

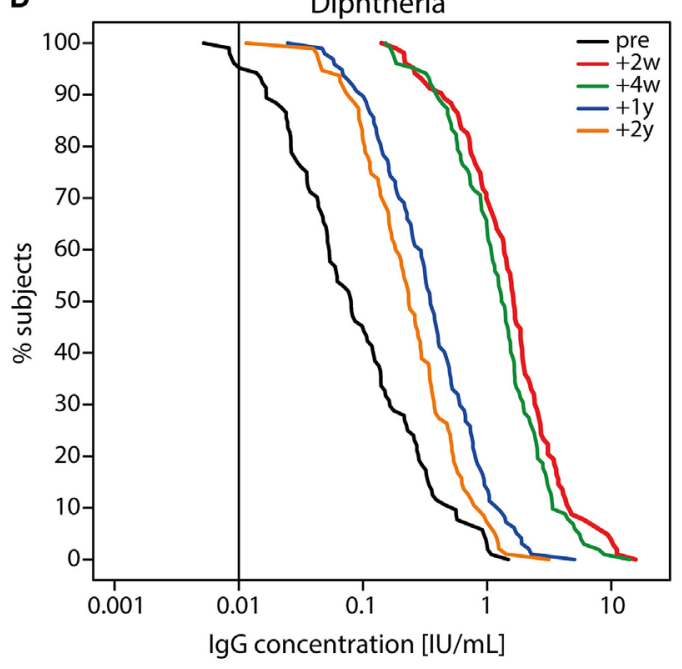

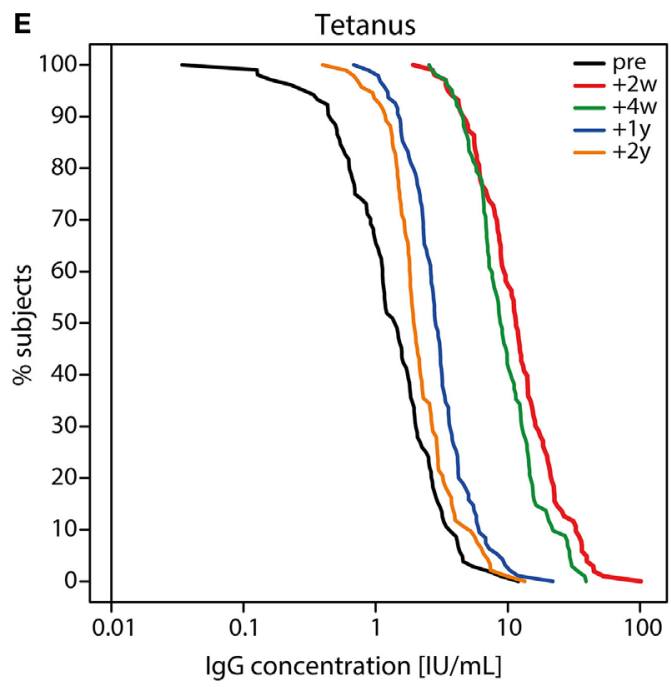

FIGURE 2 | Reverse cumulative distribution curves of IgG levels before and after a tetanus, diphtheria, and acellular pertussis (Tdap) booster vaccination. (A) pertussis toxin (PT), (B) filamentous hemagglutinin, (C) pertactin, (D) diphtheria toxoid, and (E) tetanus toxin specific lgG levels (IU/mL) in Dutch adults 25-29 years of age before (pre; black lines), 2 weeks (red lines), 4 weeks (green lines), 1 year (blue lines), and 2 years (orange lines) after a first Tdap booster vaccination. Note, black line represents the cut-off for protection (PT $20 \mathrm{IU} / \mathrm{mL}$ (suggestive), diphtheria and tetanus $0.01 \mathrm{IU} / \mathrm{mL}$ ). 
TABLE 1 | IgG geometric mean concentrations (IU/mL) with 95\% confidence intervals following a first adult tetanus, diphtheria, and acellular pertussis booster vaccination and percent reduction ${ }^{\mathrm{a}}$ of $\mathrm{IgG}$ antibody levels.

\begin{tabular}{|c|c|c|c|c|c|c|c|}
\hline & \multicolumn{5}{|c|}{ GMC IU/mL (95\% CI) } & \multicolumn{2}{|c|}{ Reduction (\%) } \\
\hline & Pre & +2 weeks & +4 weeks & +1 year & +2 years & 4 weeks-1 year & $1-2$ years \\
\hline PT & $\begin{array}{c}5.4 \\
(4.1-7.2)\end{array}$ & $\begin{array}{c}130 \\
(95-178)\end{array}$ & $\begin{array}{c}123 \\
(93-161)\end{array}$ & $\begin{array}{c}43 \\
(33-55)\end{array}$ & $\begin{array}{c}35 \\
(27-45)\end{array}$ & 58 & 15 \\
\hline $\mathrm{FHA}$ & $\begin{array}{c}10.6 \\
(8.4-13.2)\end{array}$ & $\begin{array}{c}404 \\
(340-480)\end{array}$ & $\begin{array}{c}339 \\
(288-399)\end{array}$ & $\begin{array}{c}132 \\
(110-158)\end{array}$ & $\begin{array}{c}108 \\
(90-131)\end{array}$ & 53 & 17 \\
\hline Prn & $\begin{array}{c}10.5 \\
(7.8-14.0)\end{array}$ & $\begin{array}{c}360 \\
(270-481)\end{array}$ & $\begin{array}{c}357 \\
(269-473)\end{array}$ & $\begin{array}{c}180 \\
(132-247)\end{array}$ & $\begin{array}{c}142 \\
(104-194)\end{array}$ & 41 & 20 \\
\hline Diphtheria & $\begin{array}{c}0.09 \\
(0.07-0.11)\end{array}$ & $\begin{array}{c}1.5 \\
(1.3-1.9)\end{array}$ & $\begin{array}{c}1.3 \\
(1.1-1.5)\end{array}$ & $\begin{array}{c}0.34 \\
(0.28-0.42)\end{array}$ & $\begin{array}{c}0.24 \\
(0.20-0.29)\end{array}$ & 66 & 25 \\
\hline Tetanus & $\begin{array}{c}1.3 \\
(1.1-1.5)\end{array}$ & $\begin{array}{c}11.6 \\
(10.1-13.4)\end{array}$ & $\begin{array}{c}9.4 \\
(8.4-10.6)\end{array}$ & $\begin{array}{c}3.0 \\
(2.6-3.3)\end{array}$ & $\begin{array}{c}2.2 \\
(1.9-2.4)\end{array}$ & 59 & 24 \\
\hline
\end{tabular}

GMC, geometric mean concentrations; Cl, confidence intervals; PT, pertussis toxin; FHA, filamentous hemagglutinin; Prn, pertactin.

a Samples were excluded if no increase in antibody concentration was observed 2 weeks post-booster compared with pre-booster, or when an increase after 4 weeks post-booster was observed.

vaccination, the IgG levels increased for all vaccine antigens and remained higher at all time points compared with pre-booster levels ( $p$-values <0.01) (Figure 2 and Table 1). Surprisingly, 8\% $(8 / 105)$ of the participants did not show a PT-IgG level $\geq 20 \mathrm{IU} / \mathrm{mL}$ at any of the time points. The IgG levels for diphtheria and tetanus were above the protective level pre-booster for most individuals and IgG levels increased upon the booster, but started to decline already after 2 weeks post-booster and progressed to decline significantly after 1 and 2 years post-booster ( $p$-values $<0.01$ ) (Figure 2). The reduction in vaccine antigen-specific IgG varied between 41 and $66 \%$ in the first year, but was more limited (15-25\%) during the second year post-booster (Table 1). Overall, the PT-IgG levels were similar between males and females, but 7/8 participants who did not have arbitrarily protective PT-IgG levels in the first month post-booster were females. At 2 years post-booster, more females showed PT-IgG levels under the protective cut-off (21/66 females, $32 \%)$ compared with males (8/34 males, $24 \%$ ).

According to the bi-exponential model, the median PT-IgG level was predicted to remain above $20 \mathrm{IU} / \mathrm{mL}$ for approximately 9 years (Figure 3). Median duration of protection against diphtheria and tetanus both $>0.01 \mathrm{IU} / \mathrm{mL}(29,30)$ was predicted to approximately last 16 and 93 years, respectively post-booster.

The avidity (GMAI) of the PT-IgG antibodies was significantly higher for 2 and 4 weeks of post-booster compared with prebooster ( $p$-values $<0.01$ ), while no differences were observed in the GMAI of Prn-IgG antibodies (Figure 4).

Seropositive PT-IgA levels were observed in $85 \%(89 / 105)$ of the participants pre-booster, and in 99\% (103/104) of the participants 2 weeks post-booster (Figure 5A). 2 and 4 weeks post-booster, the IgA levels for all three pertussis antigens had increased, but declined subsequently within the first year postbooster ( $p$-values <0.001) (Figure 5).

\section{B-cell Responses After the Tdap Booster Vaccination}

At 2 weeks post-booster, the absolute numbers of circulating B-cells and plasma-, naïve-, and memory-B-cell subsets had

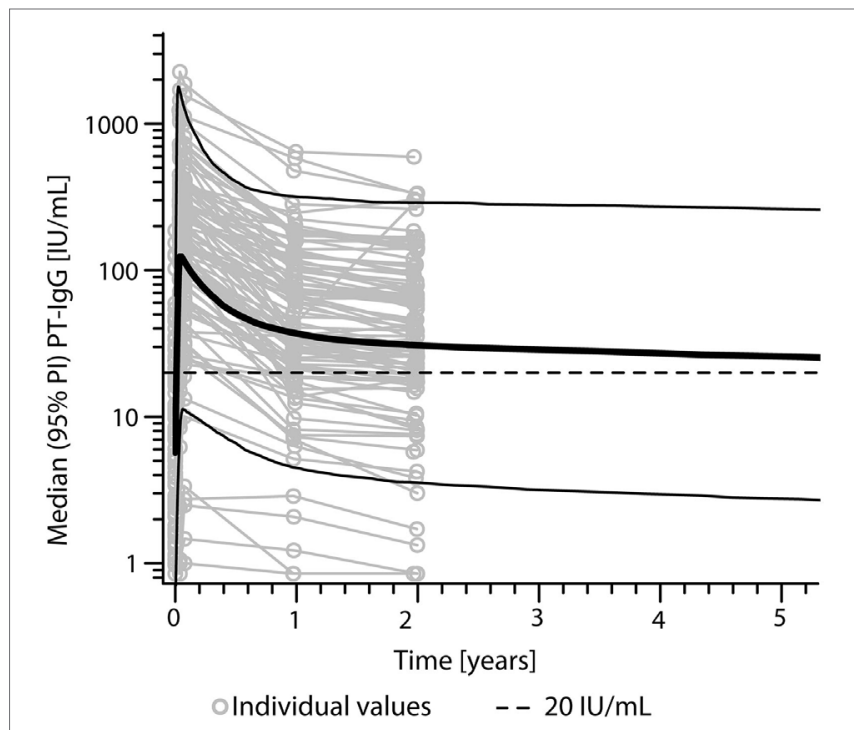

FIGURE 3 | Predicted levels of pertussis toxin (PT)-specific lgG levels (IU/mL) after a first adult tetanus, diphtheria, and acellular pertussis booster vaccination in Dutch adults 25-29 years of age using a bi-exponential model. Note, solid bold line represents the median, solid lines represents the 95\% predicted interval (95\% PI), and dotted line represents a PT-lgG concentration of $20 \mathrm{IU} / \mathrm{mL}$.

increased significantly compared with pre-booster numbers, except for natural effector B-cell numbers (Figure 6). Pre-booster, detectable numbers of vaccine antigen-specific circulating memory B-cells were observed in just a few participants (Figure 7). Following Tdap, the numbers of the vaccine antigen-specific memory B-cells $/ 10^{5} \mathrm{CD} 19^{+}$cells had increased significantly at all time points compared with pre-booster values, except for PT and Prn 2 years post-booster, but numbers had declined significantly between 4 weeks and 1 year post-booster (Figure 7). A correlation was observed between the numbers of specific memory B-cells at 2 weeks versus the specific IgG levels at 1 year and 2 years postbooster for PT and Prn $(r=0.64$ and 0.58 for PT and $r=0.65$ and 0.66 for Prn, respectively; $p$-values $<0.01$ ) (Figure 8). 

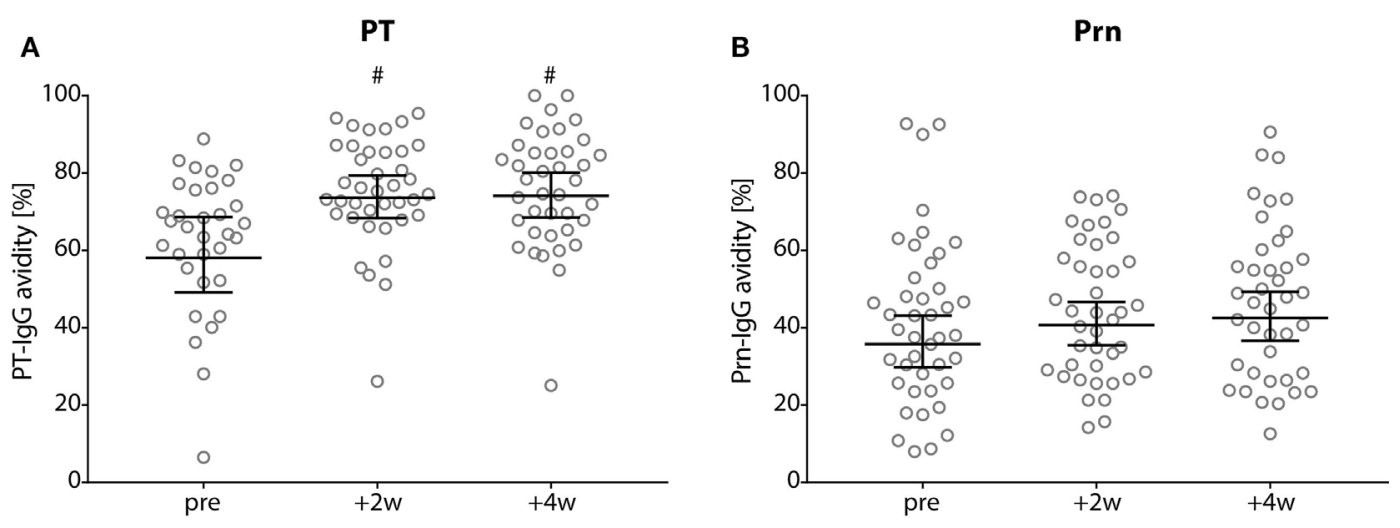

FIGURE 4 | Avidity of pertussis toxin (PT)- and Prn-lgG antibodies. (A) PT and (B) pertactin avidity index in Dutch adults 25-29 years of age before (pre), 2 weeks, and 4 weeks after a first tetanus, diphtheria, and acellular pertussis booster vaccination. Note, black lines represents the geometric mean percentage with $95 \%$ confidence interval, ${ }^{*} p$-value $<0.01$ compared with pre-booster levels.

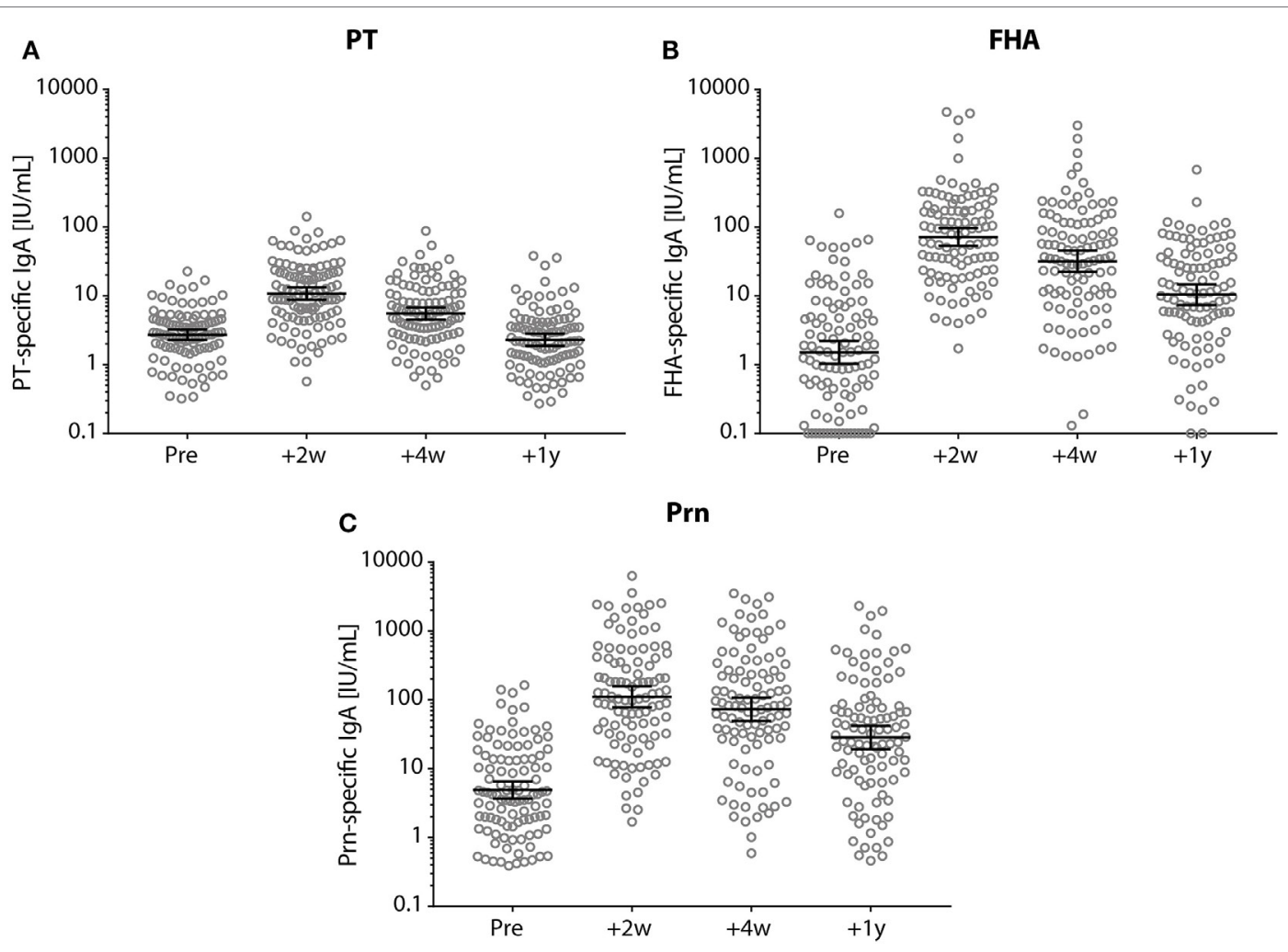

FIGURE 5 | IgA antibody levels before and after a tetanus, diphtheria, and acellular pertussis (Tdap) booster vaccination. (A) Pertussis toxin (PT), (B) filamentous hemagglutinin, and (C) pertactin (Prn)-specific lgA levels (IU/mL) in Dutch adults 25-29 years of age before (pre), 2 weeks, 4 weeks, and 1 year after a first Tdap booster vaccination. Note, black lines represent the geometric mean concentration with 95\% confidence interval. Each time point was significantly different compared with other time points.

\section{T-Cell Cytokine Responses After the Adult Tdap Booster Vaccination}

In general, the production of IFN- $\gamma$, IL-13, and IL-17 cytokines increased significantly at all time points post-booster vaccination compared with pre-booster values (Figure 9; Figure S1 in Supplementary Material). Similar levels were observed at 2 and
4 weeks and again at 1 year and 2 years following Tdap (data 4 weeks and 2 years post-booster not shown). Pertussis-specific IFN- $\gamma$ production and FHA-specific IL-13 production decreased significantly between 2 weeks and 1 year post-booster (Figure 9). Only low pertussis-specific IL-10 production was observed both pre- and post-booster (data not shown). 


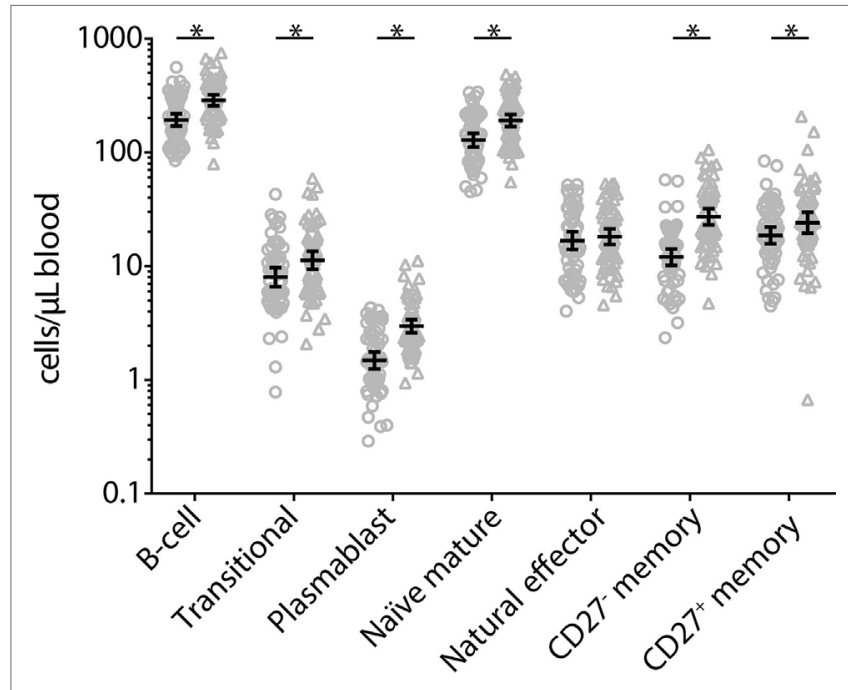

FIGURE 6 | Absolute numbers of B-cell and B-cell subsets before (circles) and 2 weeks after (triangles) a first tetanus, diphtheria, and acellular pertussis booster vaccination in Dutch adults 25-29 years of age. Gating of populations (all SSClow): B-cell: CD45+CD19+; translational: CD45+CD27-CD38+; plasmablast: $\mathrm{CD}^{4} 5^{+} \mathrm{CD} 27^{+} \mathrm{CD} 38^{+}$; naïve mature: $\mathrm{CD} 45^{+} \mathrm{CD} 27^{-} \lg { }^{+} \mathrm{CD} 38^{\mathrm{dim}}$; natural effector: CD45+CD27+lgD+CD38 ${ }^{\text {dim; }}$ CD27- memory: CD45+CD27-lgD-CD38 dim; CD27+ memory: CD45+CD27+lgD-CD38 dim. Note, black solid line represents the geometric mean numbers with corresponding 95\% confidence intervals, ${ }^{\star} p$-value $<0.05$.

\section{DISCUSSION}

In this study, we demonstrated that systemic IgG levels against the pertussis vaccine antigens PT, FHA, and Prn persisted at higher levels for at least 2 years after a first adult aP booster vaccination in young Dutch adults 25-29 years of age, who had been primed in infancy with whole-cell pertussis vaccine. A limited antibody decay was observed during the second year post-booster with antibody levels against PT above $20 \mathrm{IU} / \mathrm{mL}$ in at least $70 \%$ of the participants and an estimated median duration of protection for about 9 years. The numbers of PT- and Prn-specific B-cells observed at 2 weeks post-booster correlated with the corresponding IgG antibody levels after 1 year and 2 years. Furthermore, the booster enhanced Th1, Th2, and Th17 cytokine production for at least 2 years.

Using the same vaccine antigen dose, the adult Tdap booster vaccination in this study induced 1.5-4 times higher PT-IgG levels compared with previous studies $(15,31,32)$, which were conducted between 1997 and 2002 in a period with presumed lower circulation of $B$. pertussis than nowadays $(17,18)$. Our participants were, therefore, most likely more frequently exposed to $B$. pertussis. This is underlined by the fact that the majority of our participants showed pre-booster PT-IgA levels, that further increased post-booster. IgA responses are not induced by aP vaccines in infants (22), but exposure to B. pertussis induces systemic pertussis-specific IgA-producing memory B-cells in children and
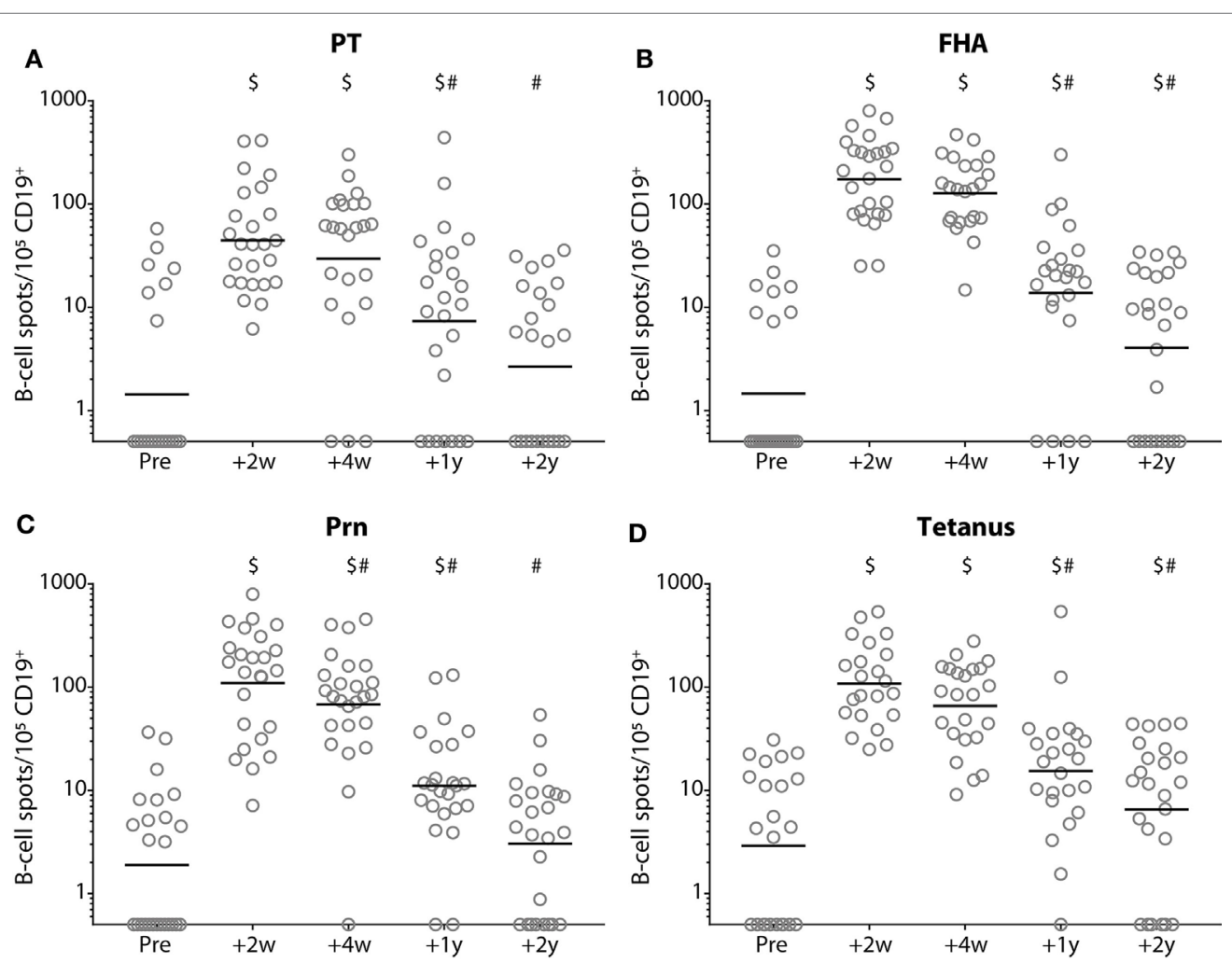

FIGURE 7 | Numbers of memory B-cells before and after a tetanus, diphtheria, and acellular pertussis (Tdap) booster vaccination. The numbers of (A) pertussis toxin, (B) filamentous hemagglutinin, (C) pertactin, and (D) tetanus toxoid-specific lgG-producing memory B-cells/100,000 CD19+ cells in Dutch adults 25-29 years of age before (pre), 2 weeks, 4 weeks, 1 year, and 2 years after a first Tdap booster vaccination. Note, black solid line represents the geometric mean number, $\$$ indicates significant increase compared with numbers pre-booster ( $p$-value <0.05) and \# indicates significant decrease compared with previous time point(s) post-booster ( $p$-value <0.05). 

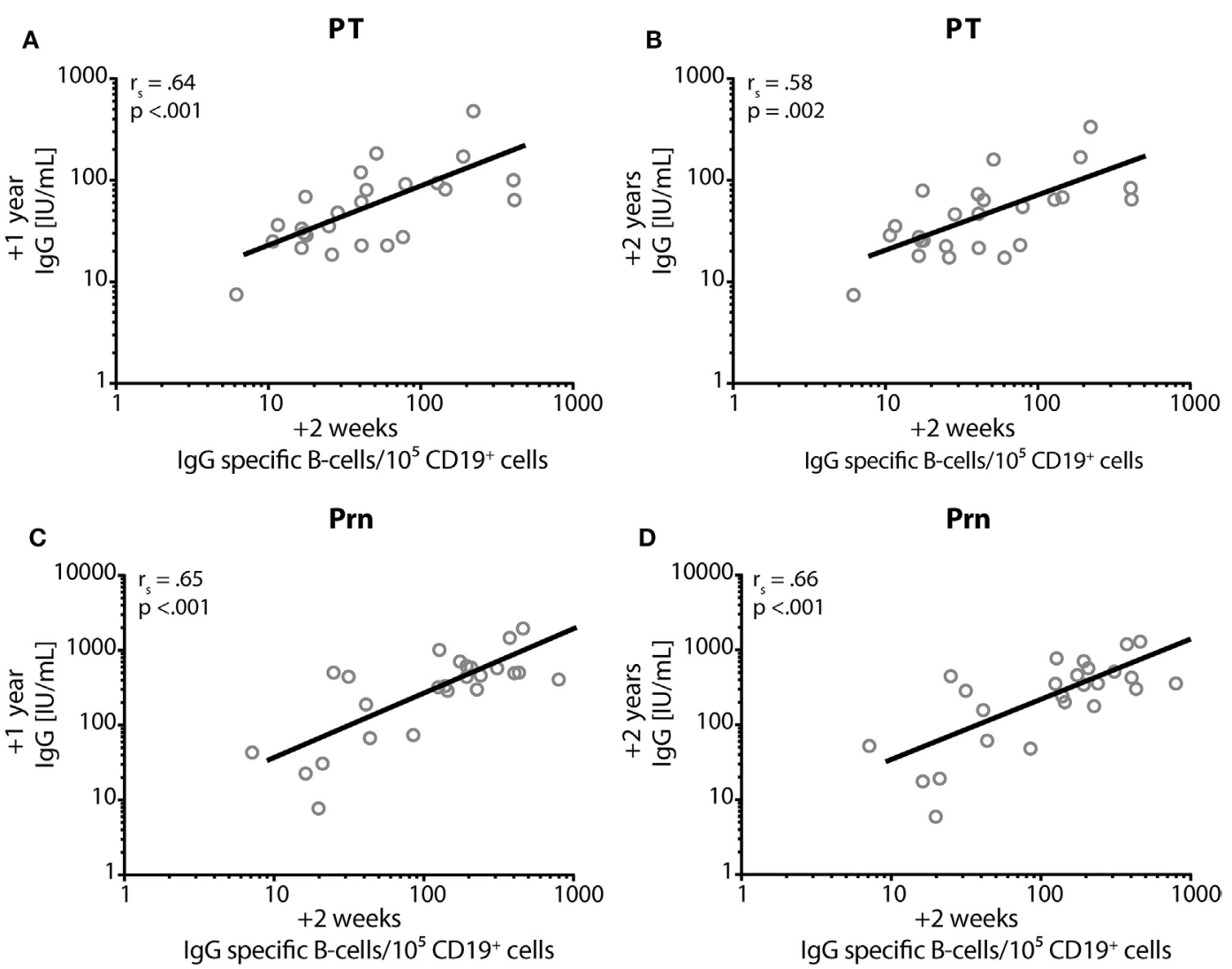

FIGURE 8 | Correlation between IgG and memory B-cells. Spearman's correlation coefficient (rs) between the numbers of IgG-specific memory B-cells/105 CD19+ cells (X-axis) at 2 weeks post-booster and the specific lgG levels in IU/mL (on the $y$-axis) at 1 year post-booster (A,C) and at 2 years post-booster (B,D) for pertussis toxin; $(\mathbf{A}, \mathbf{B})$ and for pertactin; (C,D). $p=p$-value.

adults $(22,33)$. Therefore, the presence of IgA antibodies prebooster and their rise post-booster may result from the activation of pre-existing pertussis-specific memory B-cells induced by previous $B$. pertussis contact in life, indicative of enhanced B. pertussis circulation nowadays. Together, the high pertussis circulation, compared to a population that is not or only minimally boosted with pertussis infections, alters pertussis immunity with enhanced antibody levels and cellular immunity upon a booster vaccination.

Using a bi-exponential antibody decay model with the arbitrarily defined level of protection of $\geq 20 \mathrm{IU} / \mathrm{mL}$ (23), the median duration of protective PT-IgG levels in our study was estimated to last up to 9 years after the Tdap booster. Although a power function decay model can also be used to determine antibody persistence, this model results in even more prolonged antibody persistence (34). Therefore, we prefer to use the more conservative bi-exponential model. We need to point out that the young adults in our study have been primed with $\mathrm{wP}$ vaccines during infancy, as is the case for the majority of the current adult Dutch population.

In this study, the highest pertussis-specific IgG levels were seen at day 14 post-booster followed by a slight decrease at day 28. In line with this, Halperin et al. reported increased IgG levels from day 7 with a peak around day 14 (35), and Kirkland et al. reported comparable IgG levels at 2 and 4 weeks, both after a Tdap booster (36), though using lower vaccine antigen concentrations compared with our study $(35,36)$. Other pertussis booster studies measured serological responses from 4 weeks post-booster onward (15, 37-39). Since peak IgG levels will be missed with sample collections from 4 weeks onward, vaccine antibody responses could be measured already around day 14 post-booster.

The higher IgG responses upon Tdap vaccination due to presumed recall of memory B-cells induced by a previous B. pertussis infection is reflected by the high numbers of pertussis-specific IgG memory B-cells after the booster, and the significantly higher absolute numbers of recirculating B-cell subsets. In line with this, Hendrikx et al. found similar numbers of PT-specific memory $\mathrm{B}$-cells in pre-adolescents after a second aP booster vaccination. In contrast, post-booster numbers of FHA- and Prn-specific memory B-cells were higher in adults, probably a result of more natural boosting compared with pre-adolescents. The numbers of pertussis-specific circulating memory B-cells, a month after vaccination of adolescents correlate with antibody levels a year post vaccination suggesting that memory B-cells at least partly will differentiate into plasma cells upon vaccination (40). Although the homing of the pertussis-specific memory B-cells normally occurs quickly, waning circulating IgG levels during the second year was limited, probably by the presence of long-lived plasma cells in the 

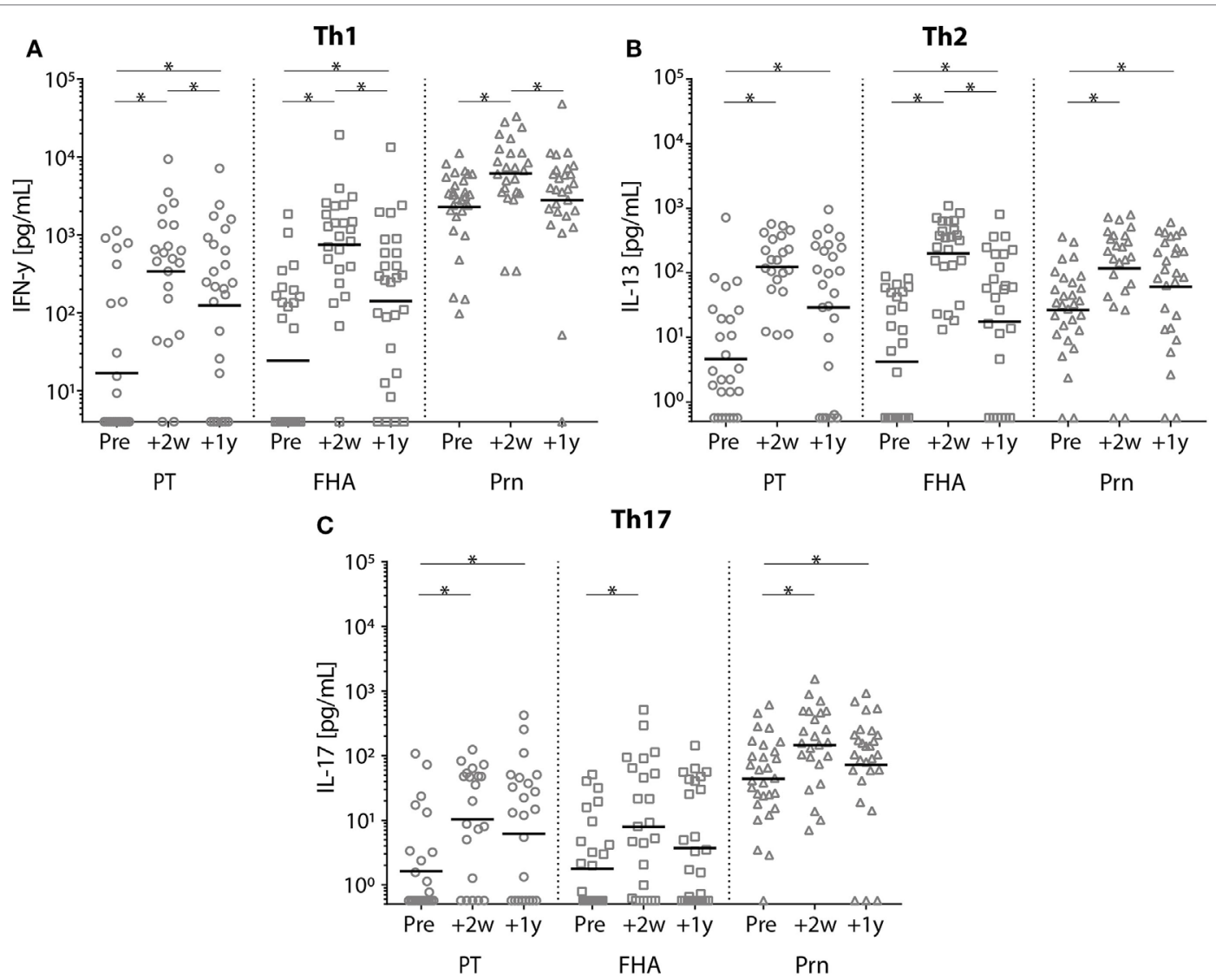

FIGURE 9 | Cytokine levels of stimulated T-cells before and after a tetanus, diphtheria, and acellular pertussis (Tdap) booster vaccination. (A) Interferon-gamma, (B) interleukin-13, and (C) IL-17 cytokine concentrations ( $\mathrm{pg} / \mathrm{mL}$ ) in the supernatants of T-cells stimulated with heat inactivated pertussis toxin (PT) (circles), filamentous hemagglutinin (squares), or pertactin (Prn) (triangles) in Dutch adults 25-29 years of age before 2 weeks and 1 year after a first Tdap booster vaccination. Note, black lines represents the geometric mean concentration; ${ }^{*} p$-value $<0.05$.

bone-marrow. Others found no correlation between circulating memory B-cells and antibody levels for diphtheria and tetanus in steady state conditions. This suggests that peripheral memory B cells and antibody-secreting plasma cells may partly represent independently regulated cell populations and may play different roles in the maintenance of protective immunity (41). The induction of memory B-cells and long-lived plasma cells by the adult booster vaccination might contribute to long-term protection against pertussis.

In agreement with other studies, the adult booster vaccination resulted in increased levels of Th1, Th2, and Th17 cytokines $(42,43)$. However, Huygen et al. did not find increased Th1 levels upon the same vaccination in pregnant women or their age-matched controls (38). Also, a pre-adolescent Tdap booster in children 9 years of age did not enhance T-cell responses (44), which we explained at the time by the high pre-booster levels already induced by a booster vaccination 5 years earlier. So far, just one study investigated the influence of pertussis priming vaccines on adult T-cell responses after a Tdap booster vaccination (43). That study showed a general Th2-dominated immune response after an aP booster in adults primed with aP vaccines during infancy, while wP-primed adults showed a Th1 dominated response (43). Since Th1 cells are essential for bacterial clearance and associated with protection (45), the increased pertussis-specific Th1 levels observed in our wP-primed adults post-booster, could possibly confer protection against pertussis, while this may be less in aPprimed adults with a Th2-dominated response.

The increase in the number of pertussis-related deaths in infants during the epidemic of 2010 in California (10) and that of 2012 in the UK (11), led to the implementation of maternal pertussis booster vaccinations (9). Maternal aP vaccinations are very effective in preventing pertussis in infants in the time window from birth until their first routine pertussis immunization, even with low anti-PT antibody levels at 2 months of age $(<15 \mathrm{IU} / \mathrm{mL})$ (46-48). In several countries, pregnant women are advised to be vaccinated during every pregnancy $(38,49)$. The persistence of high PT-IgG antibody levels reported here could indicate that the repeated administration of a Tdap booster vaccination might not be necessary for the majority of pregnant women. IgG antibody kinetics after an aP booster vaccination in pregnant women should be studied in more detail. Also, attention must be paid to potential non-responders to aP vaccinations, since these comprise $10 \%(7 / 70)$ of our female study participants.

The switch from wP to aP vaccines during infancy in 2005 , will bring the first Dutch aP-primed cohort reaching the age of 18 years in 2023. However, other countries have already 
used aP vaccines in the infant immunization program for more than two decades. Since protection against clinical pertussis wanes faster after priming with aP vaccines compared with ${ }_{w P}$ vaccines (50), women at childbearing age primed with aP vaccines, may experience the consequences of less longer persistence of pertussis-specific antibodies after booster vaccination. Therefore, the effectiveness of adult and maternal Tdap vaccinations and antibody persistence deserves further study, accounting for previous vaccinations and current $B$. pertussis exposure in the population.

To conclude, we showed a robust immune response and persistence of high pertussis IgG antibody levels after a Tdap booster vaccination in Dutch adults 25-29 years of age. These adults have been primed with $\mathrm{wP}$ vaccines during infancy and might benefit from the booster vaccine by an elevated immune response to pertussis. Maternal aP vaccination is currently the best strategy to protect newborns from pertussis. Long-term follow-up of antibody levels in women vaccinated with aP during pregnancy could elucidate the necessity to vaccinate during every pregnancy. In addition, Tdap booster responses in growing cohorts of aPprimed individuals reaching childbearing age should be further investigated.

\section{ETHICS STATEMENT}

Written informed consent was obtained at the start of the study. The study was approved by the Medical Ethics Review Committee North Holland (METC-NH, Alkmaar, the Netherlands) and registered at the European clinical trials database (2013-005355-32) and the Dutch trial register (www.trialregister.nl; NTR4494).

\section{REFERENCES}

1. Davis SF, Strebel PM, Cochi SL, Zell ER, Hadler SC. Pertussis surveillance United States, 1989-1991. MMWR CDC Surveill Summ (1992) 41(8):11-9.

2. van der Maas NA, Mooi FR, de Greeff SC, Berbers GA, Spaendonck MA, de Melker HE. Pertussis in the Netherlands, is the current vaccination strategy sufficient to reduce disease burden in young infants? Vaccine (2013) 31(41):4541-7. doi:10.1016/j.vaccine.2013.07.060

3. Campbell P, McIntyre P, Quinn H, Hueston L, Gilbert GL, McVernon J. Increased population prevalence of low pertussis toxin antibody levels in young children preceding a record pertussis epidemic in Australia. PLoS One (2012) 7(4):e35874. doi:10.1371/journal.pone.0035874

4. Jackson DW, Rohani P. Perplexities of pertussis: recent global epidemiological trends and their potential causes. Epidemiol Infect (2013) 142(4):672-84. doi:10.1017/S0950268812003093

5. Wensley A, Hughes GJ, Campbell H, Amirthalingam G, Andrews N, Young N, et al. Risk factors for pertussis in adults and teenagers in England. Epidemiol Infect (2017) 145(5):1025-36. doi:10.1017/S0950268816002983

6. Schwartz KL, Kwong JC, Deeks SL, Campitelli MA, Jamieson FB, MarchandAustin A, et al. Effectiveness of pertussis vaccination and duration of immunity. CMAJ (2016) 188(16):E399-406. doi:10.1503/cmaj.160193

7. Clark TA, Bobo N. CDC update on pertussis surveillance and Tdap vaccine recommendations. NASN Sch Nurse (2012) 27(6):297-300. doi:10.1177/1942 $602 X 12452443$

8. European Centre for Disease Prevention and Control. Recommended Immunisations for Pertussis. (2015). Available from: http://vaccine-schedule.ecdc. europa.eu/Pages/Scheduler.aspx (Accessed: 12 December, 2015).

9. Agentschap Zorg, Gezondheid, Zwangerschap en vaccinaties. Een Vroege Bescherming Voor Je Baby. (2017). Available from: https://www.vlaanderen.

\section{AUTHOR CONTRIBUTIONS}

$\mathrm{SL}, \mathrm{GB}$, and $\mathrm{A}-\mathrm{MB}$ were involved in the conception, planning, study design, and participant enrollment. SL, DR, MLB, MJB, and PG performed laboratory analysis. SL and AM performed statistical analysis. SL, ES, GB, and A-MB interpreted data and wrote the manuscript. All authors agreed to submit for publication.

\section{ACKNOWLEDGMENTS}

The authors would like to thank all participants in this study and the nurses of PreMeo for performing the clinical procedures. Additionally, we would like to thank Dr. Tom Wolfs (UMC Utrecht) for acting as the independent physician during this study. From the national institute of public health and the environment (RIVM), we thank Peter Schuurman and Marjan Kuijer for their excellent assistance in the measurements of the blood samples and Deborah Kleijne, Renée van Boxtel, Anke Smits, and Rogier Bos for their assistance in the clinical procedures.

\section{FUNDING}

This work was supported by the Dutch Ministry of Health.

\section{SUPPLEMENTARY MATERIAL}

The Supplementary Material for this article can be found online at https://www.frontiersin.org/articles/10.3389/fimmu.2018.00681/ full\#supplementary-material.

be/nl/gezin-welzijn-en-gezondheid/kinderen/vaccinatie-tegen-kinkhoest-voor-zwangere-vrouwen-en-volwassenen (Accessed: 15 June, 2017).

10. Winter K, Glaser C, Watt J, Harriman K, Centers for Disease C, Prevention. Pertussis epidemic - California, 2014. MMWR Morb Mortal Wkly Rep (2014) 63(48):1129-32.

11. Donegan K, King B, Bryan P. Safety of pertussis vaccination in pregnant women in UK: observational study. BMJ (2014) 349:g4219. doi:10.1136/bmj. g4219

12. Cherry JD. Why do pertussis vaccines fail? Pediatrics (2012) 129(5):968-70. doi:10.1542/peds.2011-2594

13. Burns DL, Meade BD, Messionnier NE. Pertussis resurgence: perspectives from the working group meeting on pertussis on the causes, possible paths forward, and gaps in our knowledge. J Infect Dis (2014) 209(Suppl 1):S32-5. doi:10.1093/infdis/jit491

14. Mooi FR, Van Der Maas NA, De Melker HE. Pertussis resurgence: waning immunity and pathogen adaptation - two sides of the same coin. Epidemiol Infect (2014) 142(4):685-94. doi:10.1017/S0950268813000071

15. Le T, Cherry JD, Chang SJ, Knoll MD, Lee ML, Barenkamp S, et al. Immune responses and antibody decay after immunization of adolescents and adults with an acellular pertussis vaccine: the APERT study. J Infect Dis (2004) 190(3):535-44. doi:10.1086/422035

16. McIntyre PB, Turnbull FM, Egan AM, Burgess MA, Wolter JM, Schuerman LM. High levels of antibody in adults three years after vaccination with a reduced antigen content diphtheria-tetanus-acellular pertussis vaccine. Vaccine (2004) 23(3):380-5. doi:10.1016/j.vaccine.2004.05.030

17. de Greeff SC, de Melker HE, van Gageldonk PG, Schellekens JF, van der Klis FR, Mollema L, et al. Seroprevalence of pertussis in the Netherlands: evidence for increased circulation of Bordetella pertussis. PLoS One (2010) 5(12):e14183. doi:10.1371/journal.pone.0014183 
18. Barkoff AM, Grondahl-Yli-Hannuksela K, He Q. Seroprevalence studies of pertussis: what have we learned from different immunized populations. Pathog Dis (2015) 73(7):ftv050. doi:10.1093/femspd/ftv050

19. Buisman AM, de Rond CG, Ozturk K, Ten Hulscher HI, van Binnendijk RS. Long-term presence of memory B-cells specific for different vaccine components. Vaccine (2009) 28(1):179-86. doi:10.1016/j.vaccine.2009.09.102

20. van der Lee S, Stoof SP, van Ravenhorst MB, van Gageldonk PGM, van der Maas NAT, Sanders EAM, et al. Enhanced Bordetella pertussis acquisition rate in adolescents during the 2012 epidemic in the Netherlands and evidence for prolonged antibody persistence after infection. Euro Surveill (2017) 22(47). doi:10.2807/1560-7917.ES.2017.22.47.17-00011

21. van Gageldonk PG, van Schaijk FG, van der Klis FR, Berbers GA. Development and validation of a multiplex immunoassay for the simultaneous determination of serum antibodies to Bordetella pertussis, diphtheria and tetanus. J Immunol Methods (2008) 335(1-2):79-89. doi:10.1016/j.jim.2008.02.018

22. Hendrikx LH, Ozturk K, de Rond LG, de Greeff SC, Sanders EA, Berbers GA, et al. Serum IgA responses against pertussis proteins in infected and Dutch $\mathrm{wP}$ or aP vaccinated children: an additional role in pertussis diagnostics. PLoS One (2011) 6(11):e27681. doi:10.1371/journal.pone.0027681

23. Long SS, Welkon CJ, Clark JL. Widespread silent transmission of pertussis in families: antibody correlates of infection and symptomatology. J Infect Dis (1990) 161(3):480-6. doi:10.1093/infdis/161.3.480

24. Hendrikx LH, Berbers GA, Veenhoven RH, Sanders EA, Buisman AM. IgG responses after booster vaccination with different pertussis vaccines in Dutch children 4 years of age: effect of vaccine antigen content. Vaccine (2009) 27(47):6530-6. doi:10.1016/j.vaccine.2009.08.052

25. Berkowska MA, Driessen GJ, Bikos V, Grosserichter-Wagener C, Stamatopoulos K, Cerutti A, et al. Human memory B cells originate from three distinct germinal center-dependent and -independent maturation pathways. Blood (2011) 118(8):2150-8. doi:10.1182/blood-2011-04-345579

26. van der Lee S, Kemmeren JM, de Rond LGH, Ozturk K, Westerhof A, de Melker HE, et al. Elevated immune response among children 4 years of age with pronounced local adverse events after the fifth diphtheria, tetanus, acellular pertussis vaccination. Pediatr Infect Dis J (2017) 36(9):e223-9. doi:10.1097/ INF.0000000000001620

27. de Jager W, te Velthuis H, Prakken BJ, Kuis W, Rijkers GT. Simultaneous detection of 15 human cytokines in a single sample of stimulated peripheral blood mononuclear cells. Clin Diagn Lab Immunol (2003) 10(1):133-9.

28. van Ravenhorst MB, Marinovic AB, van der Klis FR, van Rooijen DM, van Maurik M, Stoof SP, et al. Long-term persistence of protective antibodies in Dutch adolescents following a meningococcal serogroup C tetanus booster vaccination. Vaccine (2016) 34(50):6309-15. doi:10.1016/j.vaccine.2016.10.049

29. Galazka AM. The Immunological Basis for Immunisation. Diphtheria. Geneva: World Health Organization (1993).

30. Galazka AM. The Immunological Basis for Immunisation. Tetanus. Geneva: World Health Organization (1993).

31. Grimprel E, von Sonnenburg F, Sanger R, Abitbol V, Wolter JM, Schuerman LM. Combined reduced-antigen-content diphtheria-tetanus-acellular pertussis and polio vaccine (dTpa-IPV) for booster vaccination of adults. Vaccine (2005) 23(28):3657-67. doi:10.1016/j.vaccine.2005.02.013

32. Turnbull FM, Heath TC, Jalaludin BB, Burgess MA, Ramalho AC. A randomized trial of two acellular pertussis vaccines (dTpa and pa) and a licensed diphtheria-tetanus vaccine (Td) in adults. Vaccine (2000) 19(6):628-36. doi:10.1016/S0264-410X(00)00252-8

33. van Twillert I, Bonacic Marinovic AA, Kuipers B, van Gaans-van den Brink JA, Sanders EA, van Els CA. Impact of age and vaccination history on long-term serological responses after symptomatic $B$. pertussis infection, a high dimensional data analysis. Sci Rep (2017) 7:40328. doi:10.1038/srep40328

34. Teunis PF, van Eijkeren JC, de Graaf WF, Marinovic AB, Kretzschmar ME. Linking the seroresponse to infection to within-host heterogeneity in antibody production. Epidemics (2016) 16:33-9. doi:10.1016/j.epidem.2016.04.001

35. Halperin BA, Morris A, Mackinnon-Cameron D, Mutch J, Langley JM, McNeil SA, et al. Kinetics of the antibody response to tetanus-diphtheria-acellular pertussis vaccine in women of childbearing age and postpartum women. Clin Infect Dis (2011) 53(9):885-92. doi:10.1093/cid/cir538
36. Kirkland KB, Talbot EA, Decker MD, Edwards KM. Kinetics of pertussis immune responses to tetanus-diphtheria-acellular pertussis vaccine in health care personnel: implications for outbreak control. Clin Infect Dis (2009) 49(4):584-7. doi:10.1086/603555

37. Mertsola J, Van Der Meeren O, He Q, Linko-Parvinen A, Ramakrishnan G, Mannermaa L, et al. Decennial administration of a reduced antigen content diphtheria and tetanus toxoids and acellular pertussis vaccine in young adults. Clin Infect Dis (2010) 51(6):656-62. doi:10.1086/655825

38. Huygen K, Cabore RN, Maertens K, Van Damme P, Leuridan E. Humoral and cell mediated immune responses to a pertussis containing vaccine in pregnant and nonpregnant women. Vaccine (2015) 33(33):4117-23. doi:10.1016/j. vaccine.2015.06.108

39. Kovac M, Rathi N, Kuriyakose S, Hardt K, Schwarz TF. Immunogenicity and reactogenicity of a decennial booster dose of a combined reducedantigen-content diphtheria-tetanus-acellular pertussis and inactivated poliovirus booster vaccine (dTpa-IPV) in healthy adults. Vaccine (2015) 33(22): 2594-601. doi:10.1016/j.vaccine.2015.03.104

40. Hendrikx LH, Felderhof MK, Ozturk K, de Rond LG, van Houten MA, Sanders EA, et al. Enhanced memory B-cell immune responses after a second acellular pertussis booster vaccination in children 9 years of age. Vaccine (2011) 30(1):51-8. doi:10.1016/j.vaccine.2011.10.048

41. Amanna IJ, Carlson NE, Slifka MK. Duration of humoral immunity to common viral and vaccine antigens. N Engl J Med (2007) 357(19):1903-15. doi:10.1056/ NEJMoa066092

42. Livingston KA, Jiang X, Stephensen CB. CD4 T-helper cell cytokine phenotypes and antibody response following tetanus toxoid booster immunization. J Immunol Methods (2013) 390(1-2):18-29. doi:10.1016/j.jim.2013.01.001

43. Bancroft T, Dillon MB, da Silva Antunes R, Paul S, Peters B, Crotty S, et al. Th1 versus $\mathrm{Th} 2 \mathrm{~T}$ cell polarization by whole-cell and acellular childhood pertussis vaccines persists upon re-immunization in adolescence and adulthood. Cell Immunol (2016) 30(4-305):35-43. doi:10.1016/j.cellimm.2016.05.002

44. Schure RM, de Rond L, Ozturk K, Hendrikx L, Sanders E, Berbers G, et al. Pertussis circulation has increased T-cell immunity during childhood more than a second acellular booster vaccination in Dutch children 9 years of age. PLoS One (2012) 7(7):e41928. doi:10.1371/journal.pone.0041928

45. Allen AC, Mills KH. Improved pertussis vaccines based on adjuvants that induce cell-mediated immunity. Expert Rev Vaccines (2014) 13(10):1253-64. doi:10.1586/14760584.2014.936391

46. Amirthalingam G, Andrews N, Campbell H, Ribeiro S, Kara E, Donegan K, et al. Effectiveness of maternal pertussis vaccination in England: an observational study. Lancet (2014) 384(9953):1521-8. doi:10.1016/S0140-6736(14)60686-3

47. Dabrera G, Amirthalingam G, Andrews N, Campbell H, Ribeiro S, Kara E, et al. A case-control study to estimate the effectiveness of maternal pertussis vaccination in protecting newborn infants in England and Wales, 2012-2013. Clin Infect Dis (2015) 60(3):333-7. doi:10.1093/cid/ciu821

48. Hardy-Fairbanks AJ, Pan SJ, Decker MD, Johnson DR, Greenberg DP, Kirkland $\mathrm{KB}$, et al. Immune responses in infants whose mothers received Tdap vaccine during pregnancy. Pediatr Infect Dis J (2013) 32(11):1257-60. doi:10.1097/INF.0b013e3182a09b6a

49. Omer SB. Maternal immunization. N Engl J Med (2017) 376(25):2497. doi:10.1056/NEJMra1509044

50. Klein NP, Bartlett J, Fireman B, Baxter R. Waning Tdap effectiveness in adolescents. Pediatrics (2016) 137(3):e20153326. doi:10.1542/peds.2015-3326

Conflict of Interest Statement: SL, DR, M-LZ-B, MB, PG, AM, GB, and A-MB have no conflicts of interest. ES declares to have received grant support for vaccine studies from Pfizer and GSK.

Copyright (ㄷ) 2018 van der Lee, van Rooijen, de Zeeuw-Brouwer, Bogaard, van Gageldonk, Marinovic, Sanders, Berbers and Buisman. This is an open-access article distributed under the terms of the Creative Commons Attribution License (CC BY). The use, distribution or reproduction in other forums is permitted, provided the original author(s) and the copyright owner are credited and that the original publication in this journal is cited, in accordance with accepted academic practice. No use, distribution or reproduction is permitted which does not comply with these terms. 